\title{
QUANTIFICAÇÃO DE BIOMASSA E ESTIMATIVA DE ESTOQUE DE CARBONO EM UMA FLORESTA MADURA NO MUNICÍPIO DE VIÇOSA, MINAS GERAIS ${ }^{1}$
}

\author{
Sabina Cerruto Ribeiro², Laércio Antônio Gonçalves Jacovine ${ }^{3}$, Carlos Pedro Boechat Soares ${ }^{3}$, \\ Sebastião Venâncio Martins ${ }^{3}$, Agostinho Lopes de Souza ${ }^{3}$ e Aurea Maria Brandi Nardelli ${ }^{4}$
}

RESUMO - O objetivo deste trabalho foi quantificar a biomassa de fuste sem casca e o carbono estocado em uma floresta madura localizada no Município de Viçosa (MG). A quantificação da biomassa foi feita pelo método não destrutivo, por meio do uso de uma densidade média da madeira das espécies de maior valor de importância. Foram contabilizadas 319 espécies arbóreas, pertencentes a 177 gêneros e 60 famílias. A quantificação da biomassa do fuste sem casca resultou em estimativas de 166,67 t.ha ${ }^{-1}$, o que correspondeu a 83,34 tC.ha-1. As estimativas obtidas para a floresta madura podem ser usadas como referência para o estabelecimento de projetos de florestamento/reflorestamento, no âmbito do Mecanismo de Desenvolvimento Limpo, estabelecido no Protocolo de Quioto.

Palavras-chave: Mata Atlântica, biomassa acima do solo e Protocolo de Quioto.

\section{QUANTIFICATION OF BIOMASS AND ESTIMATION OF CARBON STOCK IN A MATURE FOREST IN THE MUNICIPAL DISTRICT OF VIÇOSA, MINAS GERAIS}

\begin{abstract}
The objective of this study was to quantify the stem biomass without bark and the carbon stock in a mature forest located in the municipal district of Viçosa $(M G)$. The biomass quantification was performed using the non-destructive method, by the use of a mean wood density of species of greater importance value. Three hundred and nineteen tree species were registered, belonging to 177 genera and 60 families. The quantification

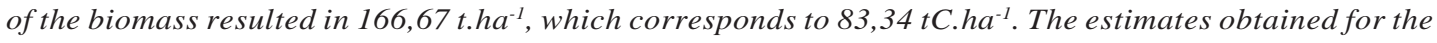
mature forest can be used as a reference for the establishment of afforestation/reforestation projects in the scope of the Clean Development Mechanism.
\end{abstract}

Keywords: Atlantic Forest, above-ground biomass and Kyoto Protocol.

\section{INTRODUÇÃO}

O território brasileiro possui cerca de $64 \%$ de sua extensão ocupada por florestas nativas (ABRAF, 2006). Desse percentual, $15 \%$ correspondem à área do bioma Mata Atlântica. Entretanto, cerca de $92 \%$ da sua formação original já foi desmatada (SOS MATA ATLÂNTICA, 2007).

Apesar da devastação acentuada, a Mata Atlântica abriga enorme riqueza biológica e alto grau de endemismo, características que contribuíram para torná-la um hotspot, que são áreas onde são encontradas grandes concentrações de espécies endêmicas e apresentam altas taxas de perda de habitat (MYERS et al., 2000). Por isso, ações de conservação e, principalmente, de recuperação que venham garantir a manutenção da biodiversidade da fauna e flora, da água, das condições climáticas e de outros serviços ambientais essenciais à manutenção e melhoria da qualidade de vida da população são necessárias na atualidade.

\footnotetext{
${ }^{1}$ Recebido em 10-03-2008 e aceito para publicação em 23.06.2009.

${ }^{2}$ Programa de Pós-Graduação em Ciência Florestal da UFV. E-mail:<sabina_ribeiro@ yahoo.com.br>.

${ }^{3}$ Universidade Federal de Viçosa, UFV, Brasil. E-mail: <jacovine@ufv.br>, <csoares@ufv.br> e <venancio@ufv.br>.

${ }^{4}$ Doutora em Ciência Florestal, auditora e revisora técnica do Grupo SGS nas áreas de Sustentabilidade e de Mudanças Climáticas. E-mail: <aur@sgsssc.general.com.br>.
} 
Entre os diversos serviços ambientais prestados pelas florestas, destacam-se o sequestro e estocagem do carbono, em função da intensificação do efeito-estufa e do consequente aquecimento global. Esses fenômenos ocorrem devido ao aumento da concentração dos gases de efeito-estufa, principalmente dióxido de carbono $\left(\mathrm{CO}_{2}\right)$, metano $\left(\mathrm{CH}_{4}\right)$ e óxido nitroso $\left(\mathrm{N}_{2} \mathrm{O}\right)$, provenientes de emissões antrópicas.

Visando mitigar esses efeitos, criou-se o Protocolo de Quioto, cujo objetivo principal foi a redução das emissões de gases de efeito-estufa em 5,0\% durante o período de 2008 a 2012, que corresponde ao primeiro período de compromisso. O Protocolo entrou oficialmente em vigor em fevereiro de 2005 e trouxe como inovação três mecanismos de flexibilização: Comércio de Emissões, Implementação Conjunta e Mecanismo de Desenvolvimento Limpo (MDL), pelo qual é possível obter as Reduções Certificadas de Emissões (RCEs), que são um dos tipos de créditos de carbono existentes.

Entre esses três mecanismos de flexibilização, apenas o MDL permite a participação de países em desenvolvimento como o Brasil, sendo, portanto, uma forma de o país inserir-se no mercado de créditos de carbono.

O crescente aumento da demanda de projetos de MDL, em virtude da ascensão do mercado de créditos de carbono, torna a quantificação do carbono estocado na biomassa florestal ferramenta importante, já que os dados gerados podem ser considerados fontes primárias de informação para a proposição de novos projetos no âmbito do MDL. Além disso, há o reconhecimento de que as florestas constituem o maior reservatório de carbono de todos os ecossistemas terrestres e funcionam, em muitos casos, como sumidouros de carbono, o que corrobora a sua inclusão em projetos de MDL (CAMPOS, 2001). No entanto, ainda existem poucos trabalhos que estimam de forma confiável o estoque de carbono nos diferentes compartimentos das florestas.

Esse fato é evidente quando se considera a Mata Atlântica. Apesar da sua importância biológica, poucos estudos foram feitos com base em medições diretas de biomassa, entre eles o de Tiepolo et al. (2002) e Burger (2005), os quais visaram ao desenvolvimento de modelos alométricos para a estimação de biomassa.
No que se refere ao uso de métodos indiretos, também não há na literatura grande volume de estudos disponíveis. Os recentes estudos disponíveis abrangem Silveira (2008) e Tanizaki-Fonseca (2000), em que o primeiro autor estimou a biomassa e o estoque de carbono pelo método da derivação de volume comercial em áreas de Floresta Ombrófila densa, enquanto o último fez a estimativa da biomassa em áreas de Mata Atlântica localizadas no Rio de Janeiro.

Tendo em vista a escassez de estudos de quantificação de biomassa no bioma Mata Atlântica e considerando o exposto anteriormente, este trabalho teve como objetivo principal verificar qual o potencial de produção de biomassa e estocagem de carbono em uma Floresta Estacional Semidecídua.

\section{MATERIAL E MÉTODOS}

O trabalho foi desenvolvido no Município de Viçosa (2045'23' 'S e 42 52 '23' 'W), localizado no Estado de Minas Gerais. O fragmento florestal estudado engloba uma área de cerca de 35 ha e situa-se no Sítio Bom Sucesso, sendo conhecido na região como "Mata do seu Nico".

A referida área, considerada um dos fragmentos florestais mais bem conservados da região, se divide em duas partes, com características bem distintas: floresta madura e capoeira. A floresta madura, onde os dados foram coletados, apresentava boa parte da sua estrutura bem conservada, com pelo menos 100 anos sem distúrbios antrópicos, segundo informações dos proprietários.

O clima da região, segundo a classificação de Köppen, é Cwa, mesotérmico úmido, com verões chuvosos e invernos secos. A precipitação pluvial média anual é de $1.248 \mathrm{~mm}$ e a umidade anual relativa do ar, de 80,6\% (SOARES JÚNIOR, 2000). A temperatura média anual é de $21^{\circ} \mathrm{C}$ (SILVA et al. apud CASTELLANI, 2006). Os solos predominantes da região são o Latossolo Vermelho-Amarelo álico nos topos de morros e nas encostas e o Podzólico Vermelho-Amarelo câmbico nos terraços (REZENDE, 1971; CÔRREA, 1984). A altitude da região é de 670 $\mathrm{m}$, com relevo variando de ondulado a montanhoso (SILVA, 2003). Segundo Veloso et al. (1991), a área de estudo pertence à formação Floresta Estacional Semidecidual Montana. 
A caracterização das principais espécies florestais foi feita com base nos estudos de Campos (2006), Irsigler (2002) e Santos (2005), os quais foram realizados anteriormente na área de estudo e apresentavam o levantamento fitossociológico da vegetação. A confirmação e atualização dos nomes científicos e das famílias foram feitas com base no site do Missouri Botanical Garden (w³ TROPICOS, 2007).

Além da listagem de espécies, dos estudos de Campos (2006), Irsigler (2002) e Santos (2005), foram obtidos dados de densidade absoluta (DA), densidade relativa (DR), frequência absoluta (FA), frequência relativa (FR), dominância absoluta (DoA), dominância relativa (DoR) e valor de importância (VI).

A coleta de dados quantitativos no campo foi feita considerando-se uma distribuição sistemática de linhas de amostragem e de distância entre as parcelas, de forma que fossem eliminados os efeitos de borda. Dessa forma, foram estabelecidas cinco linhas de amostragem, cada uma com duas parcelas de $10 \mathrm{~m}$ x $50 \mathrm{~m}$, de forma que todo o fragmento fosse amostrado, conforme a Figura 1. Em cada uma das parcelas, foram medidas a altura total $\left(\mathrm{H}_{\mathrm{t}}\right)$ e a Circunferência à Altura do Peito (CAP) das árvores com CAP $\geq 15,70 \mathrm{~cm}(\geq 5 \mathrm{~cm}$ de DAP).

Em cada parcela foram calculados o número de indivíduos por hectare (N/ha), área basal por hectare (AB/ha), volume de fuste por hectare (VF/ha), diâmetro médio (q) e altura média de Lorey (H). Além disso, foram obtidos os valores mínimo, médio e máximo de cada parâmetro, incluindo o DAP, bem como os desvios-padrão.

O volume do fuste sem casca de árvores individuais, no estágio sucessional da floresta madura, foi calculado pelo emprego da equação $1\left(r_{\mathrm{yw}}=0,989\right)$, conforme CETEC (1995):

$$
\begin{aligned}
V f_{m} & =0,000057 \times D A P^{1,778841} \times H t^{1,024876} \\
& \text { em que: }
\end{aligned}
$$

$V f_{m}=$ volume de fuste sem casca, em $\mathrm{m}^{3} ;$

$D A P=$ diâmetro à altura do peito, em cm; e $H_{t}=$ altura total, em $\mathrm{m}$.

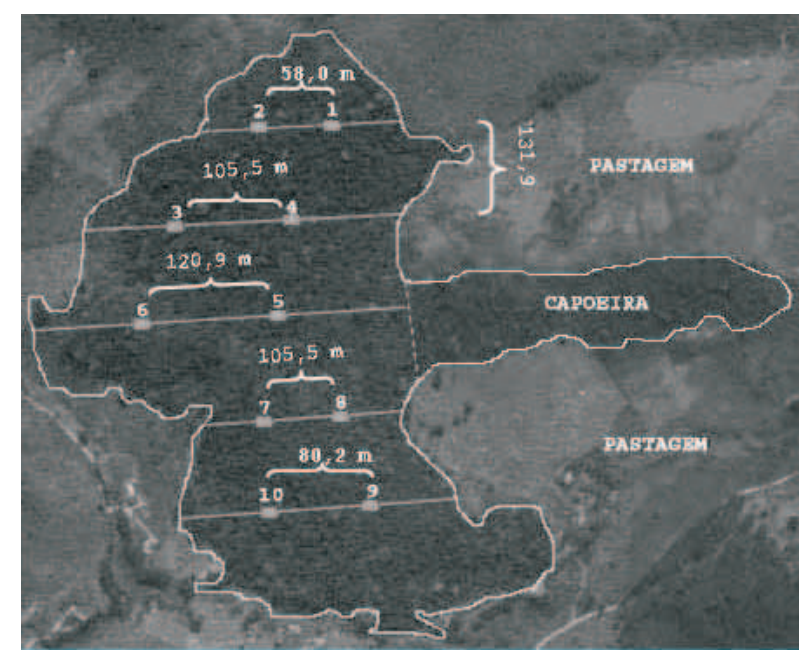

Figura 1 - Posicionamento das parcelas na floresta madura. Figure 1 - Plot's positioning at mature forest.

A estimativa da biomassa de fuste sem casca foi realizada usando-se o método não destrutivo, em função da impossibilidade de utilização do método destrutivo, devido a restrições de ordens legal e operacional. Assim, foi avaliada apenas a biomassa do fuste sem casca e não de outros compartimentos florestais, como galhos, folhas, casca e lianas.

O método indireto de quantificação de biomassa baseia-se no uso de relações empíricas entre a biomassa e outras variáveis da árvore (DAP, altura total etc.) (SALATI, 1994), relações essas expressas por meio de modelos estatísticos (SANQUETTA e BALBINOT, 2004). Alguns cuidados devem ser tomados na sua aplicação, a fim de se evitar erro significativo no cálculo da biomassa: a análise criteriosa das situações de campo (ex. árvores ocas) e a amostragem representativa da área (ARAÚJO et al., 1999).

Esse métodoé, muitas vezes, considerado alternativa mais precisa do que o método direto, visto que neste último as informações obtidas costumam vir de parcelas de pequeno tamanho, em pequeno número e selecionadas de forma intencional, geralmente em áreas que sejam mais representativas do todo (BROWN et al., 1989). Essa conduta pode introduzir erros de tendência nas estimativas, o que pode levar a super ou subestimativas da biomassa média da floresta avaliada.

Considerando-se o uso do método não destrutivo, foi feita, assim, a seleção das espécies consideradas representativas da área, com base nos dados de densidade

R. Árvore, Viçosa-MG, v.33, n.5, p.917-926, 2009 
relativa (DR) e valor de importância (VI), obtidos a partir dos estudos de Campos (2006), Irsigler (2002) e Santos (2005). A partir dessa listagem, outra seleção foi feita de forma que apenas as espécies que aparecessem em dois ou mais estudos fossem selecionadas.

A seguir, obtiveram-se os valores de densidade básica para cada uma das espécies selecionadas, com base em estudos já existentes (STEEGE et al., 2000; LORENZI, 2002a,b; IBAMA, 2007b). A densidade básica da espécie Euterpe edulis, como não estava disponível, foi determinada em laboratório, segundo a norma NBR 11941 (ABNT, 2003).

A partir dos valores de densidade básica obtidos, já convertidos em $\mathrm{kg} . \mathrm{m}^{-3}$, calculou-se a densidade básica média $(\bar{d})$ de toda a floresta madura, ponderada pelo valor de cobertura, conforme a equação 2 :

$$
\bar{d}=\sum_{i=1}^{n} D b_{i} \times\left(\frac{V C_{i}}{\sum_{i=1}^{n} V C_{i}}\right)
$$

em que: $n=$ número de espécies selecionadas;

$D b_{i}=$ densidade básica da i-ésima espécie selecionada, em kg. $\mathrm{m}^{-3}$; e

$V C_{i}=$ média do valor de cobertura das i-ésimas espécies selecionadas nos três estudos, em porcentagem.

Como a densidade básica do Euterpe edulis foi muito baixa, os indivíduos dessa espécie foram identificados e medidos separadamente em cada parcela, a fim de estimar a sua biomassa separadamente, de forma a se obter maior precisão nos resultados.

A biomassa da madeira presente no fuste de cada árvore foi estimada, excluindo-se os indivíduos de Euterpe edulis, pela multiplicação da densidade básica média da madeira pelos volumes de fuste sem casca (equação 1), conforme a equação 3 .

$$
\begin{aligned}
& \qquad B=\bar{d} \times \hat{V f} \\
& \text { em que: } \\
& B=\text { biomassa do fuste, em } \mathrm{kg} ; \\
& \bar{d}=\text { densidade básica média da madeira, em kg. } \mathrm{m}^{-3} ; \mathrm{e} \\
& \hat{V f}=\text { volume estimado de fuste sem casca, } \mathrm{em} \mathrm{m}^{3} \text {. }
\end{aligned}
$$

A seguir, a biomassa obtida apenas para a espécie Euterpe edulis foi somada à biomassa calculada para a floresta madura, obtendo-se, assim, a estimativa final de biomassa de fuste sem casca da floresta madura.

O carbono estocado na biomassa do fuste sem casca foi estimado por meio da multiplicação das estimativas de biomassa obtidas pelo fator 0,5 , considerando-se que a biomassa seca contém aproximadamente $50 \%$ de carbono (FUKUDA et al., 2003; SOARES e OLIVEIRA, 2002; FANG et al., 2001). Em seguida, o estoque de carbono foi extrapolado para toneladas por hectare.

\section{RESULTADOS}

\subsection{Caracterização das espécies florestais da floresta madura}

A partir da seleção de espécies na floresta madura, foi possível contabilizar 319 espécies arbóreas, pertencentes a 177 gêneros e 60 famílias botânicas. As seis famílias mais representativas floristicamente foram: Myrtaceae com 35 espécies (10,97\%), Lauraceae com $28(8,78 \%)$, Rubiaceae com 18 (5,64\%), Euphorbiaceae 17 (5,33\%) e Leguminosae e Meliaceae, ambas com 15 espécies $(4,70 \%)$ cada uma. Essas famílias contribuíram com 40,12\% do total de espécies listadas.

Os gêneros mais ricos, isto é, aqueles que apresentaram maior número de espécies, foram: Ocotea (Lauraceae) com 12 espécies, Inga (Leg.- Mimosoideae) com 8 e Guatteria (Annonaceae), Psychotria (Rubiaceae) e Trichilia (Meliaceae) com 7 espécies cada uma.

\subsection{Estimativa dos parâmetros quantitativos}

Para a elaboração da estrutura paramétrica da floresta madura, os indivíduos foram divididos em 22 classes de diâmetro com amplitude de classe igual a $5 \mathrm{~cm}$. De acordo com a Figura 2, a distribuição diamétrica da floresta apresenta-se como um J-invertido, em que $60 \%$ dos indivíduos estavam presentes na primeira classe $(5-10 \mathrm{~cm})$.

Os parâmetros populacionais avaliados estão apresentados na Tabela 1. A análise dos valores de N/ha, AB/ha, VF/ha, q, DAP e H obtidos apontou para valores médios de 1.920, 33,39 $\mathrm{m}^{2} \cdot \mathrm{ha}^{-1}, 235,86 \mathrm{~m}^{3} \cdot \mathrm{ha}^{-1}$, $15,04 \mathrm{~cm}, 11,6 \mathrm{~cm}$ e 19,4 m, respectivamente. 
Tabela 1 -Amplitude e variação dos parâmetros populacionais da floresta madura. Table 1 - Amplitude and variation of population parameters in the mature forest.

\begin{tabular}{|c|c|c|c|c|}
\hline Variáveis & Mínimo & Máximo & Média & Desvio padrão \\
\hline N/ha & 1.120 & 2.720 & 1.920 & 418 \\
\hline $\mathrm{AB}\left(\mathrm{m}^{2} \cdot \mathrm{ha}^{-1}\right)$ & 23,38 & 49,17 & 33,39 & 9,20 \\
\hline $\operatorname{VF}\left(\mathrm{m}^{3} \cdot \mathrm{ha}^{-1}\right)$ & 153,02 & 480,39 & 235,86 & 105,78 \\
\hline $\mathrm{q}(\mathrm{cm})$ & 11,79 & 19,92 & 15,04 & 2,85 \\
\hline DAP (cm) & 5,0 & 119,7 & 11,6 & 9,1 \\
\hline $\mathrm{H}(\mathrm{m})$ & 1,5 & 40,0 & 19,4 & 6,9 \\
\hline
\end{tabular}

Tabela 2 - Densidade Relativa (DR), Valor de Importância (VI) e Densidade Básica da Madeira (DBM) das espécies selecionadas na floresta madura.

Table 2 - Relative Density (RD), Importance Value (IV) and Wood Basic Density (WBD) of the selected species in the mature forest.

\begin{tabular}{|c|c|c|c|}
\hline Espécies selecionadas & $\mathrm{DR}(\%)$ & $\mathrm{VI}(\%)$ & $\operatorname{DBM}\left(\mathrm{t} . \mathrm{m}^{-3}\right)$ \\
\hline Euterpe edulis Mart. & 37,38 & 28,09 & 0,17 \\
\hline Pseudopiptadenia contorta (DC.) G.P. Lewis \& M.P. Lima & 2,15 & 11,38 & 0,75 \\
\hline Virola gardneri (A. DC.) Warb. & 2,26 & 9,09 & 0,66 \\
\hline Guatteria nigrescens Mart. & 2,41 & 8,81 & 0,59 \\
\hline Trichilia catigua A. Juss. & 1,38 & 4,06 & 0,64 \\
\hline Astronium graveolens Jacq. & 0,57 & 3,72 & 0,97 \\
\hline Sorocea bonplandii (Baill.) W.C. Burger, Lanj. \& Wess. Boer & 2,86 & 2,66 & 0,67 \\
\hline Guarea macrophylla Vahl & 2,74 & 2,56 & 0,52 \\
\hline Sterculia chicha A. St.-Hil. ex Turpin & 1,43 & 2,51 & 0,39 \\
\hline Virola oleifera (Schott) A.C. Sm. & 0,95 & 2,27 & 0,61 \\
\hline Pouteria caimito (Ruiz \& Pav.) Radlk. & 0,84 & 2,05 & 0,95 \\
\hline Protium warmingiana March, L. & 2,02 & 1,86 & 0,75 \\
\hline Guapira opposita (Vell.) Reitz & 2,02 & 1,74 & 0,83 \\
\hline Siparuna guianensis Aubl. & 1,67 & 1,41 & 0,89 \\
\hline Colubrina glandulosa Perkins & 0,71 & 1,28 & 0,92 \\
\hline Ocotea odorifera (Vellozo) Rohwer & 0,83 & 0,96 & 0,76 \\
\hline Inga cylindrica (Vell.) Mart. & 0,83 & 0,79 & 0,48 \\
\hline Coussapoa microcarpa (Schott) Rizzini & 0,24 & 0,72 & 0,59 \\
\hline Luehea grandiflora Mart. & 0,48 & 0,70 & 0,64 \\
\hline Simira sampaioana (Standl.) Steyerm. & 0,48 & 0,66 & 0,64 \\
\hline Cryptocarya moschata Nees \& C. Mart. & 0,24 & 0,65 & 0,57 \\
\hline Hieronyma alchorneoides Allemão & 0,12 & 0,59 & 0,69 \\
\hline \multirow[t]{2}{*}{ Schefflera morototoni (Aubl.) Maguire, Steyerm. \& Frodin } & 0,48 & 0,59 & 0,62 \\
\hline & Total & $\mathbf{8 9}, 15$ & \\
\hline
\end{tabular}

\subsection{Quantificação da biomassa e do carbono estocado na floresta madura}

Foram selecionadas 23 espécies, com base nos três estudos e nos valores de densidade relativa e valor de importância, para a determinação da densidade básica média (Tabela 2).

Dessa forma, com base nos dados de densidade básica e do valor de cobertura das espécies apresentadas na Tabela 2, com exceção da espécie Euterpe edulis, obteve-se uma densidade básica média ponderada igual a $0,70 \mathrm{t} \cdot \mathrm{m}^{-3}$.

A estimativa final da biomassa de fuste sem casca e do carbono, por parcela, considerando-se a espécie Euterpe edulis, estão apresentados na Tabela 3. Obteve-se estimativa de biomassa do fuste sem casca igual a 166,67 t.ha $^{-1}$ e de estoque de carbono igual a 83,34 t.ha-1.

R. Árvore, Viçosa-MG, v.33, n.5, p.917-926, 2009 
Tabela 3 - Estimativas de biomassa de fuste sem casca $\left(\right.$ t.ha $\left.^{-1}\right)$ e carbono (t.ha-1) da floresta madura por parcela.

Table 3 - Estimates of stem biomass without bark (t.ha- $\left.{ }^{-1}\right)$ and carbon $\left(\mathrm{t}^{\left.\mathrm{h} \mathrm{h}^{-1}\right)}\right.$ per plot of mature forest.

\begin{tabular}{|c|c|c|c|c|}
\hline \multirow[t]{2}{*}{ Parcelas } & \multicolumn{3}{|c|}{ Biomassa $\left(\mathrm{t} . \mathrm{ha}^{-1}\right)$} & \multirow[t]{2}{*}{$\mathrm{C}\left(\mathrm{t} \cdot \mathrm{ha}^{-1}\right)$} \\
\hline & $\begin{array}{c}\text { Floresta } \\
\text { madura }\end{array}$ & $\begin{array}{c}\text { Euterpe } \\
\text { edulis }\end{array}$ & Total & \\
\hline 1 & 117,47 & 3,36 & 120,83 & 60,42 \\
\hline 2 & 106,48 & 0,02 & 106,50 & 53,25 \\
\hline 3 & 116,45 & 0,28 & 116,73 & 58,37 \\
\hline 4 & 138,61 & 7,53 & 146,14 & 73,07 \\
\hline 5 & 334,29 & 0,00 & 334,29 & 167,14 \\
\hline 6 & 151,77 & 2,37 & 154,13 & 77,07 \\
\hline 7 & 166,20 & 0,03 & 166,23 & 83,11 \\
\hline 8 & 150,63 & 0,69 & 151,32 & 75,66 \\
\hline 9 & 107,01 & 0,00 & 107,01 & 53,51 \\
\hline 10 & 252,37 & 11,18 & 263,55 & 131,78 \\
\hline Média & 164,13 & 2,55 & 166,68 & 83,34 \\
\hline
\end{tabular}

\section{DISCUSSÃO}

\subsection{Caracterização das espécies florestais da floresta madura}

As espécies florestais selecionadas na floresta madura compunham 60 famílias botânicas, das quais foram ressaltadas Myrtaceae, Lauraceae, Rubiaceae, Euphorbiaceae, Leguminosae e Meliaceae, por serem as famílias de maior riqueza florística. Entre essas, Myrtaceae, Lauraceae e Rubiaceae merecem destaque, por serem famílias botânicas comuns em estádios avançados de sucessão, o que condiz com o fato de estarem presentes na floresta madura (TABARELLI et al. apud PINTO et al., 2007; SILVA JÚNIOR et al., 2004).

No que se refere às espécies presentes na área de estudo, verificou-se, com base na lista oficial de espécies da flora brasileira ameaçada de extinção (IBAMA, 2007a), que as espécies Astronium fraxinifolium e Dalbergia nigra foram consideradas vulneráveis e Brosimum glaziovii, espécie rara. A presença dessas espécies destaca a importância da conservação dos fragmentos florestais, já que a maior parte da biodiversidade atual se encontra localizada neles (VIANA, 1998).

Por isso, garantir a conservação da "Mata do seu Nico" é uma forma de se preservar uma amostra da biodiversidade da região, além da sua importância na estocagem de carbono.

R. Árvore, Viçosa-MG, v.33, n.5, p.917-926, 2009

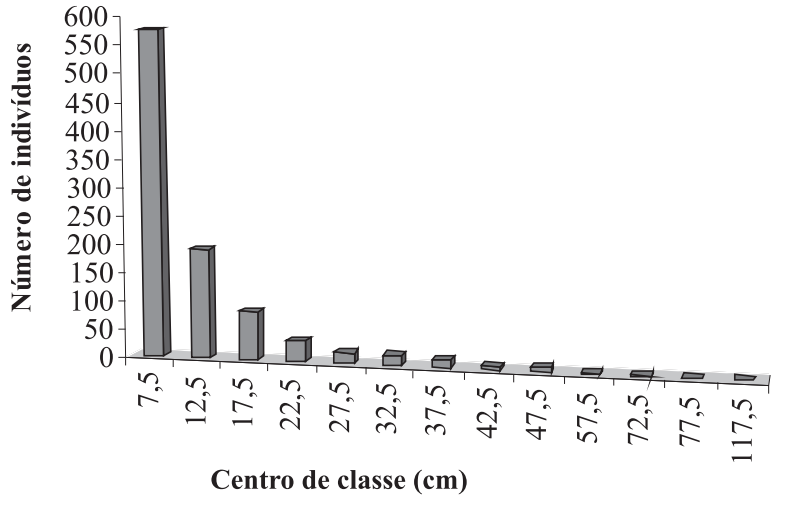

Figura 2 - Distribuição diamétrica considerando todos os indivíduos amostrados na floresta madura.

Figure 2 - Diametric distribution considering all individuals sampled in the mature forest.

\subsection{Estimativa dos parâmetros quantitativos}

A partir da estrutura diamétrica elaborada, verificou-se que ela (Figura 2) apresentou tendência a um J-invertido, ou seja, o maior número de indivíduos se encontrou nas menores classes de diâmetro, o que é um comportamento típico de florestas multiâneas (SCHAAF et al., 2006).

Os parâmetros populacionais da floresta madura (Tabela 1), por sua vez, estão de acordo com o apresentado na Resolução n 29, do CONAMA (1994), segundo a qual se consideram em estágio avançado de regeneração (neste caso, a floresta madura) fisionomias que apresentem altura média superior a $10 \mathrm{~m}$ e área basal superior a $18 \mathrm{~m}^{2} \cdot \mathrm{ha}^{-1}$. Os valores se enquadram dentro dos valores propostos pela referida Resolução, o que indica que a floresta madura estudada pode estar em estádio avançado de regeneração.

É importante ressaltar, que esses dados de referência nem sempre se aplicam, pois algumas formações florestais, apesar de estarem em estágio avançado de regeneração, podem apresentar valores de altura e de área basal inferiores aos destacados pela Resolução $\mathrm{n}^{\circ} 29$, devido a fatores como altitude e tipo de solo.

\subsection{Quantificação da biomassa e do carbono estocado na floresta madura}

As estimativas de biomassa e carbono obtidas foram semelhantes a estudos em que foram obtidas estimativas de biomassa do fuste com casca. Castilho et al. (2006), 
em um estudo em floresta madura na Amazônia central, obtiveram estimativas de biomassa do fuste variando entre 210,9 e 426,3 t.ha ${ }^{-1}$, com uma média igual a 327,8 $\pm 41,9$ t.ha ${ }^{-1}$. Saldarriaga et al. (1988), em estudo sobre o desenvolvimento sucessional na região amazônica, encontraram biomassa do fuste em quatro povoamentos de florestas maduras variando entre 107 e 145 t.ha $^{-1}$. Jordan e Uhl (1978) obtiveram estimativas de biomassa do fuste e galhos iguais a 315,66 t.ha- ${ }^{-1}$ em uma floresta localizada na bacia amazônica, mais especificamente em San Carlos de Rio Negro, Venezuela.

Comparando os resultados com os demais trabalhos citados, é preciso considerar que na grande maioria deles foram obtidas estimativas de volume de fuste com casca e não sem casca, como neste estudo. Assim, considerando que a casca corresponde, em média, à cerca de 20,5\% (WATZLAWICK et al., 2002) da biomassa total de uma árvore, observou-se que a biomassa do fuste sem casca $\left(166,67\right.$ t.ha $\left.^{-1}\right)$ obtida neste trabalho foi condizente com estudos que consideraram a casca na quantificação da biomassa.

Considerando estudos de quantificação da biomassa viva acima do solo de florestas primárias, realizados na região amazônica, observou-se que eles apresentaram valores maiores do que aqueles obtidos neste trabalho, com variações do valor de biomassa entre 230 e 490 t.ha ${ }^{-1}$. Alves et al. (1997), em estudo sobre biomassa em florestas secundárias e primárias em Rondônia, encontraram estimativas de biomassa em florestas primárias que variavam entre 290 e 495 t.ha $^{-1}$.

Nascimento e Laurance (2002) obtiveram média de biomassa acima do solo igual a 397,7 $\pm 30,0$ t.ha${ }^{1}$ em florestas intactas na Amazônia central. Brown et al. (1995) obtiveram, em uma floresta primária em Rondônia, valores de biomassa iguais a $285 \mathrm{t}^{\text {h ha }}{ }^{-1}$, com o uso de equações alométricas ajustadas com amostras destrutivas. Essa diferença de valores entre trabalho e outros estudos também pôde ser verificada em estudos de Fearnside (1997), Laurance et al. (1999) e Klinge et al. (1975).

Uma exceção foi o estudo de Folster et al. (1976) em florestas primárias e secundárias na Colômbia. Eles obtiveram estimativa da biomassa viva acima do solo igual a 180 t.ha-1 . O baixo valor obtido foi atribuído à grande presença de palmeiras no fragmento estudado, as quais eram "beneficiadas" pela alta mortalidade de folhosas devido ao vento e à seca.
Do mesmo modo, a alta densidade de palmeiras presente na "Mata do seu Nico" pode ter sido uma das causas para o valor de biomassa de fuste sem casca encontrado neste estudo. Isso porque a palmeira Euterpe edulis foi uma das espécies de maior VI na área de estudo e possui densidade básica muito baixa $(0,17$ t.m ${ }^{-3}$ ). Em virtude dessa baixa densidade, ela não apresenta alto estoque de biomassa (Quadro 3), o que, associado ao grande número de indivíduos dessa espécie no local, pode ter contribuído para que o valor final da biomassa de fuste sem casca da floresta madura fosse menor do que aqueles obtidos na Floresta Amazônica.

De qualquer forma, ao comparar os resultados dos estudos de quantificação da biomassa citados com as estimativas obtidas neste trabalho, é esperado que eles apresentem maiores valores, já que neles foram obtidas estimativas totais da biomassa viva acima do solo (tronco + galhos + folhas), enquanto neste estudo foram obtidas apenas estimativas da biomassa do fuste sem casca.

A existência de estudos que visem à quantificação do carbono estocado em diferentes estádios sucessionais é de grande relevância para projetos de florestamento e reflorestamento no âmbito do Mecanismo de Desenvolvimento Limpo, especialmente se a conservação florestal vier a se tornar prática elegível, pois é uma forma de estimar a quantidade de créditos de carbono que será gerada após certo período de tempo.

Dessa forma, observa-se que esses estudos podem vir a contribuir para a aprovação de atividades de projetos no âmbito do Mecanismo de Desenvolvimento Limpo. Assim, além dos benefícios ambientais, também serão promovidos benefícios econômicos, por meio dos créditos de carbono gerados em atividades de projetos em países em desenvolvimento, como o Brasil.

\section{CONCLUSÕES}

- A floresta estudada apresentou biomassa de fuste sem casca de 166,67 t.ha ${ }^{-1}$, evidenciando-se o potencial de produção primária da Mata Atlântica.

- O estoque de carbono médio igual a 83,34 t.ha-1, evidenciando-se a importância da floresta Atlântica no sequestro e fixação de carbono e, consequentemente, contribuindo para a minimização do efeito-estufa.

R. Árvore, Viçosa-MG, v.33, n.5, p.917-926, 2009 
- A estimativa do estoque de carbono pode ser usada como referência para o estabelecimento de projetos de florestamento/reflorestamento, no âmbito do Mecanismo de Desenvolvimento Limpo (MDL), estabelecido no Protocolo de Quioto, e gerar os denominados créditos de carbono. Ressalta-se a relevância disso para a Mata Atlântica, em virtude do grande número de áreas degradadas que essa mata possui, as quais poderiam ser passíveis de estabelecimento dos projetos de carbono.

\section{AGRADECIMENTOS}

À Sra. Terezinha, por disponibilizar o Sítio Bom Sucesso para a execução do experimento; ao Márcio e Laurindo, pelo auxílio nas coletas de campo; e ao Conselho Nacional de Desenvolvimento Científico e Tecnológico (CNPq), pela concessão da bolsa de estudo e de produtividade em pesquisa.

\section{REFERÊNCIAS}

ASSOCIAÇÃO BRASILEIRA DE NORMAS TÉCNICAS - ABNT. NBR 11941: Madeira-Determinação da densidade básica. Rio de Janeiro: 2003. 6p.

ABRAF. Anuário estatístico da ABRAF: ano base 2005. Brasília: 2006. 80p.

ALVES, D. et al. Biomass of primary and secondary vegetation in Rondônia, western Brazilian Amazon. Global Change Biology, v.3, n.5, p.451-461, 1997.

\section{ARAÚJO, T. M.; HIGUCHI, N.; CARVALHO}

JÚNIOR, J. A. Comparison of formulae for biomass content determination in a tropical rain forest site in the state of Pará, Brazil. Forest Ecology and Management, v.117, n.1, p.43-52, 1999.

BROWN, I. F. et al. Uncertainty in the biomass of Amazonian forests: An example from Rondônia, Brazil. Forest Ecology and Management, v.75, n.1-3, p.175-189, 1995.

BROWN, S.; GILLESPIE, A. J. R.; LUGO, A. E. Biomass estimation methods for tropical forests with applications to forest inventory data. Forest Science, v.35, n.4, p.881-902, 1989.

R. Árvore, Viçosa-MG, v.33, n.5, p.917-926, 2009
BURGER, D. M. Modelos alométricos para a estimativa da fitomassa de Mata Atlântica na Serra do Mar, SP. 2005. 112f. Tese (Doutorado em Ciências) - Universidade de São Paulo, São Paulo, 2005

CASTILHO, C. V. et al. Variation in aboveground tree live biomass in a central Amazonian Forest: Effects of soil and topography. Forest Ecology and Management, v.234, n.1-3, p.85-96, 2006.

CAMPOS, C. P. A conservação das florestas no Brasil, mudança do clima e o mecanismo de desenvolvimento limpo do Protocolo de Quioto. 2001. 169f.

Dissertação (Mestrado Planejamento Energético) COPPE/Universidade Federal do Rio de Janeiro, Rio de Janeiro, 2001.

CAMPOS, E. P. Florística e estrutura horizontal da vegetação arbórea de uma ravina em um fragmento florestal no município de Viçosa-MG. Revista Árvore, v.30, n.6, p.1045-1054, 2006.

FUNDAÇÃO CENTRO TECNOLÓGICO DE MINAS GERAIS - CETEC. Determinação de equações volumétricas aplicáveis ao manejo sustentado de florestas nativas no estado de Minas Gerais e outras regiões do país. Belo Horizonte: 1995. 295p.

CONSELHO NACIONAL DO MEIO AMBIENTE CONAMA Resolução $\mathbf{n}^{\mathbf{0}} \mathbf{2 9}$, de 07 de dezembro de 1994. Define vegetação primária e secundária nos estágios inicial, médio e avançado de regeneração da Mata Atlântica, considerando a necessidade de definir o corte, a exploração e a supressão da vegetação secundária no estágio inicial de regeneração no Espírito Santo Disponível em: <http://www.mma.gov.br/port/ conama/legi.cfm>. Acesso em: 5 mar. de 2007.

CORRÊA, G.F. Modelo de evolução e mineralogia da fração argila de solos do Planalto de Viçosa, MG. 1984. 87f. Dissertação (Mestrado em Solos e Nutrição de Plantas) - Universidade Federal de Viçosa, Viçosa, MG, 1984.

FANG, J. et al. Changes in forest biomass carbon storage in China between 1949 and 1998. Science, v.292, n.5525, p.2320-2322, 2001. 
FEARNSIDE, P. M. Greenhouse gases from deforestation in Brazilian Amazon: net committed emissions. Climatic Change, v.35, n.3, p.321-360, 1997.

FOLSTER, H. et al. Tropical evergreen forest site with perched water table, Magdalena-Valley, Columbia biomass and bioelement inventory of primary and secondary vegetation. Oecologia Plantarum, v.11, p.297-320, 1976.

FUKUDA, M.; IEHARA, T.; MATSUMOTO, M. Carbon stock estimates for sugi and hinoki forests in Japan. Forest Ecology and Management, v.184, n.1-3, p.1-16, 2003.

IB AMA. Flora. Disponível em:

<www.ibama.gov.br/flora/home.htm>. Acesso em: 26 fev. 2007a.

IB AMA. Database of brazilian woods. Disponível em: <http://www.ibama.gov.br/lpf/ madeira/foreword.htm>. Acesso em: 08 maio de 2007.

IRSIGLER, D. T. Composição florística e estrutura de um trecho primitivo de floresta estacional semidecidual em Viçosa, MG. 2002. 61f. Dissertação (Mestrado em Botânica) - Universidade Federal de Viçosa, Viçosa, MG, 2002.

JORDAN, C. F.; UHL, C. Biomass of a "tierra firme" forest of the Amazon Basin. Oecologia Plantarum, v.13, p.387-400, 1978.

KLINGE, H. et al. Biomass and structure in a central Amazonian rain forest. In: GOLLEY, F.B.; MEDINA, E. Tropical ecological systems: Trends in terrestrial and aquatic research. New York: Springer Verlag, 1975. p.115-122.

LAURENCE, W. F. et al. Relationship between soils and Amazon forest biomass: a landscapescale study. Forest ecology and management, v.118, n.1-3, p.127-138, 1999.

LORENZI, H. Árvores brasileiras: manual de identificação e cultivo de plantas arbóreas nativas do Brasil. Nova Odessa: Plantarum, 2002a. v.1.368p.
LORENZI, H. Árvores brasileiras: manual de identificação e cultivo de plantas arbóreas nativas do Brasil. Nova Odessa: Plantarum, 2002b. v.2. 368 p.

MYERS, N. et al. Biodiversity hotspots for conservation priorities. Nature, v.403, p.853-858, 2000 .

MISSOURI BOTANICAL GARDEN.

w⿳3 TROPICOS. Disponível em: <http:// www.mobot.org/>. Acesso em: 14 fev. 2007.

NASCIMENTO, H. E. M.; LAURANCE, W. F. Total aboveground biomass in central Amazonian rainforests: a landscape-scale study. Forest Ecology and Management, v.168, n.1-3, p.311-321, 2002.

REZENDE, S. B. Estudo da cronoseqüência em Viçosa - MG. 1971. $71 \mathrm{f}$. Dissertação (Mestrado em Fitotecnia) Universidade Federal de Viçosa, Viçosa, MG, 1971.

SALATI, E. Emissão x seqüestro de CO2 - Uma nova oportunidade de negócios para o Brasil. Sumário Executivo. In: SEMINÁRIO EMISSÃO X SEQÜESTRO DE CO2: UMA NOVA OPORTUNIDADE DE NEGÓCIOS PARA O BRASIL, 1994, Rio de Janeiro. Anais... Rio de Janeiro: CVRD, 1994. p.15-37.

SALDARRIAGA, J. G. et al. Long-term chronosequence of forest succession in the upper Rio Negro of Colombia and Venezuela. Journal of Ecology, v.76, p.938-958, 1988.

SANQUETTA, C. R.; BALBINOT, R. Metodologias para determinação de biomassa florestal. In: SANQUETTA, C. R.; BALBINOT, R.; ZILLIOTTO, M. A. SIMPÓSIO LATINO AMERICANO SOBRE FIXAÇÃO DE CARBONO, 2., 2004, Curitiba. Fixação de carbono: atualidades, projetos e pesquisas. Curitiba: 2004. Parte 5. p.77-93.

\section{SANTOS, M. L. Composição florística e estrutura de um trecho de floresta estacional semidecidual primária na Zona da Mata de Minas Gerais. 2005. 49f. Dissertação (Mestrado em Botânica) - Universidade Federal de Viçosa, Viçosa, MG., 2005.}

R. Árvore, Viçosa-MG, v.33, n.5, p.917-926, 2009 
SCHAAF, L. B. et al. Alteração na estrutura diamétrica de uma floresta ombrófila mista no período entre 1979 e 2001. Revista Árvore, v.30, n.2, p.283-295, 2006.

SILVA, F. et al. Teor e composição do óleo essencial de manjericão (Ocimum basilicum L.) em dois horários e duas épocas de colheita.

Revista Brasileira de Plantas

Medicinais, v.6, n.1, p. 33-38, 2003. apud CASTELLANI, D.C. et al. Produção de óleo essencial em catuaba (Trichilia catigua A. Juss) e negramina (Siparuna guianensis Aubl.) em função da época de colheita. Revista Brasileira de Plantas Medicinais, Botucatu, v. 8, n. 4, p. 62-65, 2006.

SILVA, A. F. et al. Composição florística e grupos ecológicos das espécies de um trecho de floresta semidecídua submontana da Fazenda São Geraldo, Viçosa-MG. Revista Árvore, v.27, n.3, p.311319, 2003.

SILVA JÚNIOR, W. M. et al. Regeneração natural de espécies arbustivo-arbóreas em dois trechos de uma Floresta Estacional Semidecidual, Viçosa, MG. Scientia Forestalis, n.66, p.169-179, 2004.

SILVEIRA, P. Métodos indiretos de estimativa do conteúdo de biomassa e do estoque de carbono em um fragmento de floresta ombrófila mista. 2008. 112f. Tese (Doutorado em Ciências Florestais ) - Universidade Federal do Paraná, Curitiba, 2008.

SOARES JÚNIOR, F. J. Composição florística e estrutura de um fragmento de floresta estacional semidecidual na Fazenda Tico-Tico, Viçosa, MG. 2000. 68f. Dissertação (Mestrado em Botânica) Universidade Federal de Viçosa, Viçosa, MG, 2000.

SOARES, C. P. B.; OLIVEIRA, M. L. R. Equações para estimar a quantidade de carbono na parte aérea de árvores de eucalipto em Viçosa, Minas Gerais. Revista Árvore, v.26, n.5, p.533-539, 2002.

SOS MATA ATLÂNTICA. Mata Atlântica. Disponível em: <http://www.sosmatatlantica.org.br>. Acesso em: 22 fev. 2007.

R. Árvore, Viçosa-MG, v.33, n.5, p.917-926, 2009
STEEGE, H. ter et al. Plant diversity in Guyana: implications for a national protected areas strategy. Disponível em: <http:// www.bio.uu.nl/ herba/Guyana/ Plant_Diversity_Guyana/>. Acesso em: 10 maio 2007.

TABARELLI, M. et al. Estudo comparativo da vegetação de dois trechos de floresta secundária no Núcleo Santa Virgínia, Parque Estadual da Serra do Mar, SP. Revista do Instituto Florestal, v.6, p.1-11, 1994. apud Pinto, S.I.C. et al. Estrutura do componente arbustivo-arbóreo de dois estádios sucessionais de floresta estacional semidecidual na Reserva Florestal Mata do Paraíso, Viçosa, MG, Brasil. Revista Árvore, Viçosa, v. 31, n. 5, p.823-833, set./out. 2007.

TANIZAKI-FONSECA, K. Impacto do uso da terra no estoque e fluxo de carbono na área de domínio da Mata Atlântica: estudo de caso, estado do Rio de Janeiro. 2000. 212f. Tese (Doutorado em Geociências) - Universidade Federal Fluminense, Niterói, 2000.

TIEPOLO, G.; CALMON, M.; FERETTI, A. R. Measuring and monitoring carbon stocks at the Guaraqueçaba climate action project, Paraná, Brazil. In: INTERNATIONAL SYMPOSIUM ON FOREST CARBON SEQUESTRATION AND MONITORING, 2002, Taipei, Taiwan. Anais... Taipei: Taiwan Forestry Research Institute, 2002. p.98-115.

VELOSO, H. P.; FILHO, A. L. R. R.; LIMA, J. C. Classificação da vegetação brasileira, adaptada a um sistema universal. Rio de Janeiro: IBGE, 1991. 125p.

VIANA, V. M. Conservação da biodiversidade em fragmentos florestais. Série Técnica IPEF, v.12, n.32, p.25-42, 1998.

WATZLAWICK, L. F. et al. Fixação de carbono em floresta ombrófila mista em diferentes estágios de regeneração. In: SANQUETTA, C. R. et al. As florestas e o carbono. Curitiba: UFPR, 2002. Parte 8. p.153-173.

R. Árvore, Viçosa-MG, v.33, n.5, p.917-926, 2009 